\section{An Energy Balance Model for Predicting Berry Temperature and Scheduling Sprinklers for Cooling in Northern Highbush Blueberry}

\author{
Fan-Hsuan Yang \\ Department of Horticulture, Agricultural and Life Science Building 4017, \\ Oregon State University, Corvallis, OR 97331
}

David R. Bryla

U.S. Department of Agriculture, Agricultural Research Service, 3420 NW Orchard Avenue, Corvallis, OR 97330

\section{R. Troy Peters}

Department of Biological Systems Engineering, Washington State University, Irrigated Agriculture Research \& Extension Center, $24106 \mathrm{~N}$. Bunn Road, Prosser, WA 99350

Additional index words. evaporative cooling, fruit quality, heat-related fruit damage, sprinkler irrigation, Vaccinium corymbosum

\begin{abstract}
Heat-related fruit damage is a prevalent issue in northern highbush blueberry (Vaccinium corymbosum L.) in various growing regions, including the northwestern United States. To help address the issue, we developed a simple climatological model to predict blueberry fruit temperatures based on local weather data and to simulate the effects of using over-canopy sprinklers for cooling the fruit. Predictions of fruit temperature on sunny days correlated strongly with the actual values $\left(R^{2}=0.91\right)$ and had a root mean-square error of $\approx 2{ }^{\circ} \mathrm{C}$. Among the parameters tested, ambient air temperature and light intensity had the greatest impact on fruit temperature, whereas wind speed and fruit size had less impact, and relative humidity had no impact. Cooling efficiency was estimated successfully under different sprinkler cooling intervals by incorporating a water application factor that was calculated based on the amount of water applied and the time required for water to evaporate from the fruit surface between the intervals. The results indicate that water temperature and nozzle flow rate affected the extent to which cooling with sprinklers reduced fruit temperature. However, prolonging the runtime of the sprinklers did not guarantee lower temperatures during cooling, because cooling efficiency declined as the temperature of the fruit approached the temperature of the irrigation water. Users could incorporate the model into weather forecast programs to predict the incidence of heat damage and could use it to make cooling decisions in commercial blueberry fields.
\end{abstract}

Received for publication 21 Sept. 2020. Accepted for publication $15 \mathrm{Jan} .2021$.

Published online 22 February 2021

Funds for this research were provided by the Oregon Blueberry Commission and the U.S. Department of Agriculture (Current Research Information System no. 2072-21000-048-00D).

We thank Fall Creek Farm and Nursery for providing plants for the experimental plots and Wilbur-Ellis Agribusiness for providing fertilizers. Mention of trademark, proprietary product, or vendor does not constitute a guarantee or warranty of the product by the U.S. Department of Agriculture and does not imply its approval to the exclusion of other products or vendors that also may be suitable.

F.-H.Y. is a former $\mathrm{PhD}$ student. Current address: Sierra Cascade Nursery, 10230 Santa Fe Drive, Ballico, CA 95303.

D.R.B. is the corresponding author. E-mail: david. bryla@usda.gov.

This is an open access article distributed under the CC BY-NC-ND license (https://creativecommons. org/licenses/by-nc-nd/4.0/). critical economically in blueberries, and how can cooling practices be optimized to prevent the damage efficiently?

Previously, Yang et al. (2019) found that visual signs of heat damage occur in northern highbush blueberry when the surface temperature of berries reached 42 to $48^{\circ} \mathrm{C}$ for 1.5 to $2 \mathrm{~h}$ in a sensitive cultivar and 3 to $3.5 \mathrm{~h}$ in a more tolerant cultivar. They also determined that the temperature of the sun-exposed berries was up to 7 to $11{ }^{\circ} \mathrm{C}$ warmer than the air temperature on hot, sunny days. Unfortunately, predictions of heat damage based simply on air-temperature measurements are not always accurate because there are other environmental factors, such as light intensity and wind, that affect the temperature of the plants and fruit (Cellier et al., 1993; Monteith and Unsworth, 2013; Saudreau et al., 2009). To estimate blueberry temperatures more effectively according to local environmental conditions, mathematical models based on energy balance are an option. In an energy balance model, the overall gain and loss of energy on an object is equal (Monteith and Unsworth, 2013). The energy flux of a fruit is estimated according to its geometry and surface characteristics, and is a function of the environmental conditions. Energy models have been widely used for predicting fruit temperature in a number of crops, including apple [Malus $\times$ sylvestris $(\mathrm{L}$.) Mill. var. domestica (Borkh.) Mansf.], peach [Prunus persica (L.) Batsch], wine grape (Vitis vinifera L.), and fig (Ficus carica L.) (Cola et al., 2009; Evans, 2004; Li et al., 2014; Patiño et al., 1994; Pitacco et al., 2000; Saudreau et al., 2007; Smart and Sinclair, 1976), but they have not been applied previously to blueberry.

Energy balance models can also be useful for predicting the efficiency of cooling systems to reduce heat damage in fruit crops. For example, Evans (2004) provided equations for estimating skin and core temperatures in apple and was able to simulate changes in fruit temperature during cooling using an irrigation system with small spray nozzles. He calculated the amount of heat removed from the apples based on estimates of water interception, sprinkler spacing, and temperature differences between the fruit and irrigation water. A simple energy balance model was likewise used to predict potential water use during evaporative cooling in wine grape (Caravia et al., 2017).

In this study, we developed an energy balance model specifically for northern highbush blueberry. Our objectives included 1) developing a model for predicting blueberry fruit temperature based on the weather conditions, 2) evaluating the impact of different weather parameters on fruit temperature, and 3) predicting the efficacy of cooling on fruit temperature based on sprinkler specifications and cooling frequency. This information is needed to design effective management practices and strategies for preventing heat damage before harvest in blueberries.

\section{Materials and Methods} 1973; Parchomchuk and Meheriuk, 1996; Pelletier et al., 2016). As more growers begin to adopt these practices, some key questions are arising, such as when is the risk of heat damage

\section{Study site}

Data for the model were collected in 2015 in a mature test planting of 'Elliott' blueberry 
established in Apr. 2004 at Oregon State University Lewis-Brown Horticultural Research Farm in Corvallis, OR (lat. $44^{\circ} 33^{\prime} \mathrm{N}$; long. $123^{\circ} 13^{\prime} \mathrm{W}$; elevation, $\left.68 \mathrm{~m}\right)$. The plants were grown $0.8-\mathrm{m}$ apart on rows of raised beds $(0.4 \mathrm{~m}$ high $\times 0.9 \mathrm{~m}$ wide). The beds were spaced $3.0 \mathrm{~m}$ apart, in an east-west direction, and were mulched every 2 to 3 years with a 5-cm-deep layer of douglas fir [Pseudotsuga menziesii (Mirb.) Franco] sawdust. Blueberry plants were hand-pruned annually in late winter. Treatments were arranged in a randomized block design with four replicated plots that were irrigated by either drip or sprinklers. Each of these treatment plots consisted of three rows of eight plants; all measurements were made in the middle row on the center six plants in the plot. Drip plots were irrigated using drip tubing (model UniRam 570; Netafim, Fresno, CA) with integrated pressurecompensating emitters $\left(2.0 \mathrm{~L} \cdot \mathrm{h}^{-1}\right)$ every $0.45 \mathrm{~m}$. Sprinkler plots were irrigated using $2.8-\mathrm{L} \cdot \mathrm{min}^{-1}$ pop-up spray heads with preinstalled, dual-spray, quarter-pattern $\left(90^{\circ}\right)$ nozzles (model 1802QDS; Rain Bird Corp., Glendora, CA). The sprinklers were used for both irrigation (night) and cooling (day) as needed. Cooling was run for $15 \mathrm{~min}$ every hour when the air temperature was $\geq 35^{\circ} \mathrm{C}$. Any water used for cooling was subtracted from the irrigation schedule. See Yang et al. (2020a) for more information on the study site.

\section{Measurements}

Fruit surface temperatures were measured at the site using 0.13-mm copper-constantan wire thermocouples (Omega Engineering Inc., Stamford, CT). The thermocouples were inserted beneath the epidermal layer of four berries per cluster. Four clusters exposed to full sun on the west side of the plants were selected randomly at a height of 1.2 to $1.5 \mathrm{~m}$ in each plot to measure berries with the greatest potential for damage (Yang et al., 2019).

Ambient air temperature and relative humidity were measured using a temperature-humidity probe (model HMP60; Vaisala, Woburn, WA). The probe was covered by a six-plate radiation shield (model 41303-5A; RM Young, Traverse City, MI) and was mounted $1.8 \mathrm{~m}$ high. Wind speed was measured at a height of $2.4 \mathrm{~m}$ above the ground using a high-performance anemometer (model 05103, RM Young). Because this sensor has a sensitivity threshold of $1 \mathrm{~m} \cdot \mathrm{s}^{-1}$, any readings that were $<1 \mathrm{~m} \cdot \mathrm{s}^{-1}$ were rounded up to $1 \mathrm{~m} \cdot \mathrm{s}^{-1}$. Total solar irradiance, diffuse irradiance, and net radiation were measured using a pyranometer (model SP-110; Apogee, Logan, UT), a sunshine sensor (model BF-5; Delta-T, Cambridge, UK), and a net radiometer (model Q*7.1; Radiation and Energy Balance Systems, Seattle, WA), respectively. Each radiation sensor was mounted at height of $3 \mathrm{~m}$.

All measurements were recorded every 5 min using data loggers (models CR-800, CR-1000, and CR-3000; Campbell Scientific, Logan, UT). Reference temperature was measured using a thermistor built into the wiring panel of the data loggers.

\section{Energy balance model}

According to the law of conservation of energy, energy cannot be created or destroyed, but can be modified in form. In a given object, the input of energy is equivalent to storage and loss of the energy. According to Evans (2004), the energy balance of fruit can be categorized into total incoming radiation $\left(R_{a b s}\right)$, emitted radiation $\left(R_{e}\right)$, sensible heat loss $(H)$, latent heat loss $(\lambda E)$, and sensible heat flux within the fruit $\left(E_{f}\right)$ (Fig. 1A). Sensible heat removal by water $\left(E_{w}\right)$ will also occur when sprinklers are run in the field for cooling or irrigation.

Total incoming and emitted radiation. Net radiation $\left(R_{n}\right)$ is the difference between $R_{a b s}$, which includes both short- and longwave radiation, and $R_{e}$. Shortwave radiation absorbed by the fruit is calculated by multiplying total shortwave radiation $\left(S_{T}\right)$ by the fraction of absorption $\left(1-\alpha_{\mathrm{f}}\right)$, where $S_{T}$ is the sum of direct and diffuse irradiance $\left(S_{b}\right.$ and $S_{d}$ ), and $\alpha_{\mathrm{f}}$ is the albedo of the fruit (Cola et al., 2009). Smart and Sinclair (1976) determined that $\alpha_{f}$ was equal to 0.22 in red wine grapes, which we assumed here was similar to blueberries. Direct light reaching the fruit was corrected $\left(S_{b}{ }^{\prime}\right)$ by dividing $S_{b}$ by the sine of the solar elevation angle $(\beta)$ (Smart and Sinclair, 1976). In this study, we simulated the hottest scenario, which is when the solar beam is normal (perpendicular) to the surface of the fruit. Incoming long-wave radiation $\left(R_{l}\right)$ includes irradiance from both the sky and the ground. The combination of the two were derived from net radiometer output $\left(R_{n}{ }^{\prime}\right)$ (measured in watts per square meter). We assumed that $\alpha_{\mathrm{f}}$ was equivalent to an orchard canopy $\left(\alpha_{\text {canopy }}\right)$, which has a value of about 0.2 (Monteith and Unsworth, 2013). Therefore, to calculate $R_{l}$, we used the following formula:

$$
R_{l}=R_{n}^{\prime}-\left(1-\alpha_{\text {canopy }}\right) S_{T} .
$$

Energy emission from the fruit, $R_{e}$, was calculated based on Stefan-Boltzmann's law. Assuming the fruit acts as a gray body, $R_{e}$ was calculated as

$$
R_{e}=\varepsilon \sigma T_{f}^{4}
$$

where $\varepsilon$ is the emissivity of the fruit $(0.97$; Monteith and Unsworth, 2013), $\sigma$ is the StefanBoltzmann constant $\left(5.67 \mathrm{E}-8 \mathrm{~W} \cdot \mathrm{m}^{-2}\right)$, and $T_{f}$ is the surface temperature of the fruit (measured in degrees Celsius).

Sensible heat loss. Sensible heat flux (measured in watts per square meter), $H$, arises because of the temperature difference between the surface of an object and the surrounding air. This heat must transfer through a boundary layer above the object before exchanging with the air. The process is defined as

$$
H=C_{p} \times \rho_{a} \times g_{H} \times\left(T_{f}-T_{a}\right),
$$

where $C_{p}$ is the specific heat of air (measured in joules per kilogram kelvin), $\rho_{a}$ is air density (measured in kilograms per cubic meter), $g_{H}$ is the heat transfer conductance (measured in meters per second) (Monteith and Unsworth, 2013), and $T_{a}$ is ambient air temperature (measured in degrees Celsius).
Heat transfer conductance, $g_{H}$, can be calculated as

$$
g_{H}=1.5 \times \frac{\kappa \mathrm{Nu}}{d},
$$

where 1.5 is a ratio to adjust a sphere to a plate based on the average Reynolds number (Re; Campbell and Norman, 1998), $\kappa$ is the thermal diffusivity of air (measured in meters squared per second), $d$ is the average diameter of a berry cluster (measured in meters), and $\mathrm{Nu}$ is the Nusselt number, which, based on the geometry of the fruit and the range of $\mathrm{Re}$ in our study, was equal to $0.34 \times \mathrm{Re}^{0.6}$ (Monteith and Unsworth, 2013).

Latent heat loss. Latent heat flux (measured in watts per square meter), $\lambda E$, is associated with the phase change of water without changing its temperature. Commonly, latent heat exchange occurs as evaporation and transpiration (Campbell and Norman, 1998; Li et al., 2014) and can be calculated as

$\lambda E=\lambda g_{v} \rho_{a} \frac{\Delta\left(T_{f}-T_{a}\right)}{P}+\lambda g_{v} \rho_{a} \frac{e_{s}\left(T_{a}\right)-e_{a}}{P}$,

where $\lambda$ is the latent heat of vaporization (measured in kilojoules per kilogram), $g_{v}$ is water vapor conductance (measured in meters per second), $\Delta$ is the slope of the saturation vapor pressure curve (measured in kilopascals per degrees Celsius), $P$ is atmospheric pressure (measured in kilopascals), $e_{s}$ $\left(T_{a}\right)$ is the saturation vapor pressure at $T_{a}$ (measured in kilopascals), and $e_{a}$ is the ambient vapor pressure (measured in kilopascals). For water vapor to transfer from intracellular airspace to the outer environment, it must pass through the cuticle $\left(g_{c}\right)$ and boundary layer $\left(g_{b l}\right)$ on the surface of the fruit. Therefore, $g_{v}$ can be written as

$$
g_{v}=\frac{1}{\frac{1}{g_{c}}+\frac{1}{g_{b l}}} .
$$

We assumed that $g_{c}$ of blueberries was equivalent to mature wine grapes $(\approx 4$ $\mathrm{mmol} \cdot \mathrm{m}^{-2} \cdot \mathrm{s}^{-1}$; Zhang and Keller, 2015) and defined $g_{b l}$ as

$$
g_{b l}=\frac{\kappa_{v}}{\delta},
$$

where $\kappa_{\mathrm{v}}$ is the thermal diffusivity of water vapor (measured in square meters per second) and $\delta$ is the boundary layer thickness (measured in millimeters). Based on Nobel (1975), $\delta$ was calculated as

$$
\delta=2.8 \sqrt{\frac{d}{u}}+\frac{0.25}{u},
$$

where $u$ is wind speed (measured in meters per second).

Sensible heat flux within the fruit. Sensible heat flux, or in other words the change of heat storage in the fruit, can be calculated as

$$
E_{f}=C_{f} \times \frac{d}{6} \times \frac{d T}{d t},
$$

where $C_{f}$ is the specific heat of fruit (4172 $\mathrm{J} \cdot \mathrm{kg}^{-1} \cdot \mathrm{K}^{-1}$; Mercali et al., 2011) and $d T / d t$ is 
A

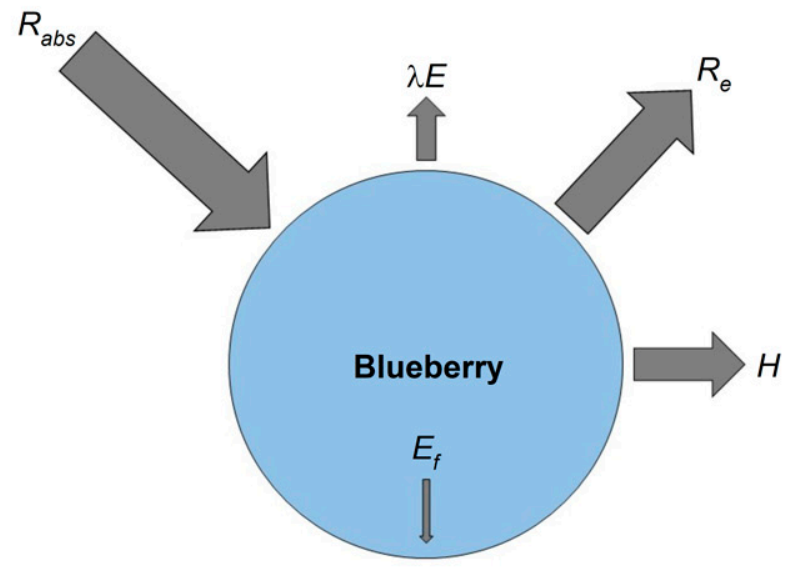

B

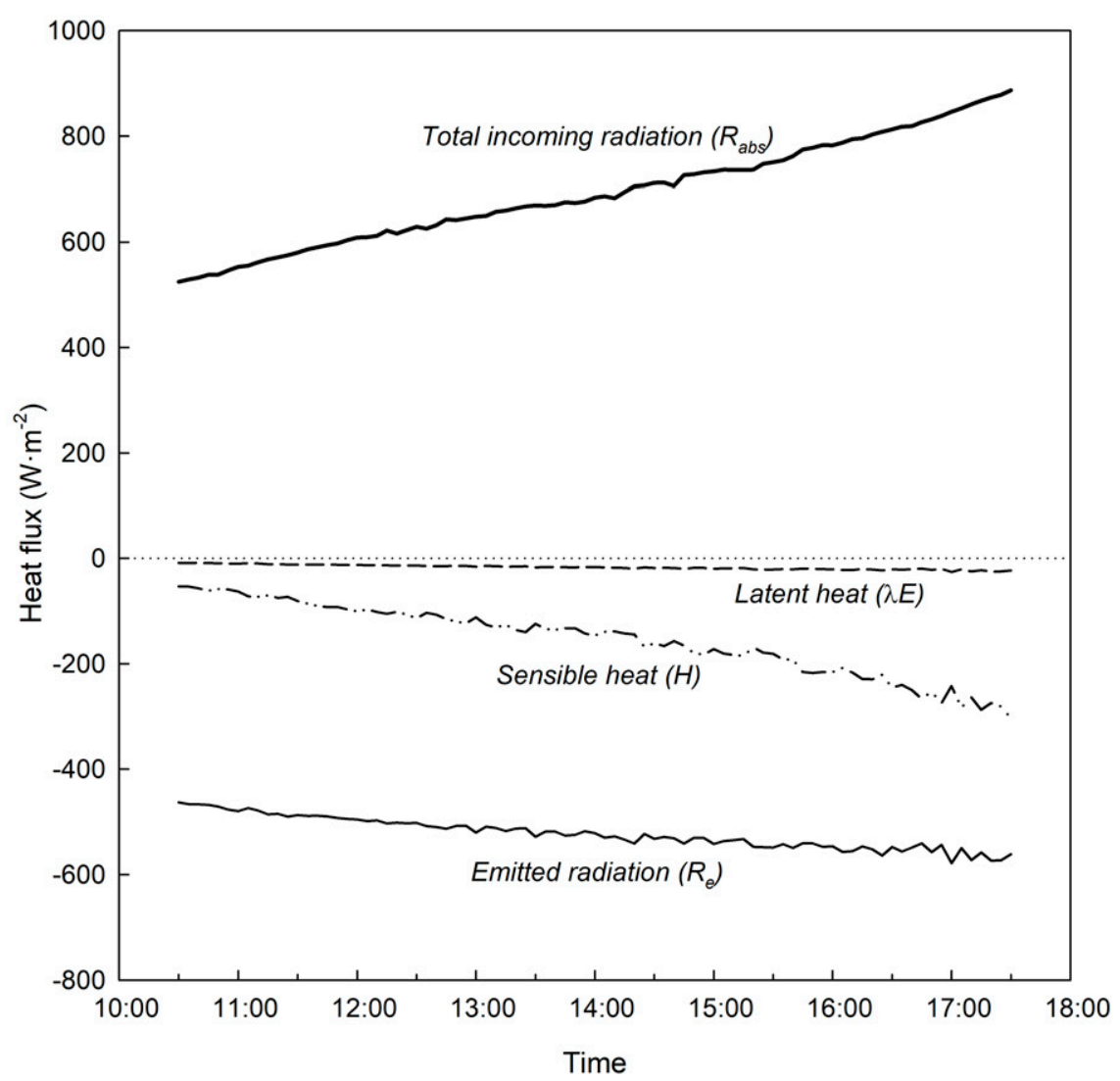

Fig. 1. Illustration of (A) the components of the heat energy balance model and (B) simulated heat fluxes at the surface of a sun-exposed blueberry. Fluxes were calculated using weather data collected in a field of 'Elliott' blueberry on 31 July 2015 (hottest day of the year). Sensible heat flux $\left(E_{f}\right)$ within the fruit accounted for $<0.5 \%$ heat loss.

the change in temperature over time in the fruit cluster.

An example of outputs from the model are illustrated in Fig. 1B. In this case, we input weather data from 31 July 2015, which was the hottest day of the year. The total amount of incoming radiation absorbed by the fruit increased from 497 to $887 \mathrm{~W} \cdot \mathrm{m}^{-2}$ between 1000 and $1800 \mathrm{HR}$ (typically the warmest period of the day). Most of the radiation rounding ambient air. In our model, sensible heat accounted for $7 \%$ to $35 \%$ of the total heat loss from the berries. Latent heat accounted for only $1 \%$ to $3 \%$ of the total energy loss, and change of heat storage accounted for a $<0.5 \%$ loss throughout this study. Because the latter term was trivial, it was excluded from the energy balance calculation. Similar changes in heat flux were observed during other days in which the model was run.

Sensible heat removal by water. In apple (Evans, 2004), heat removal by water was calculated as

$$
E_{w}=I \frac{d M a}{d t} \times\left(T_{w}-T_{f}\right) \times \frac{C}{S},
$$

where $I$ is the water interception ratio by plants, $M_{a}$ is the mass of water applied by sprinklers over time (measured in kilograms per second), $T_{w}$ is the temperature of the water at the fruit surface (measured in degrees Celsius), $C$ is a conversion factor to change kilograms per second to watts per kelvin [which is calculated by multiplying the specific heat of water $\left(4190 \mathrm{~J} \cdot \mathrm{kg}^{-1} \cdot \mathrm{K}^{-1}\right)$ by the density of water $\left.\left(1 \mathrm{~kg} \cdot \mathrm{L}^{-1}\right)\right]$, and $S$ is the spacing of the sprinklers (measured in meters squared). However, rather than calculating water interception from sprinkler flow rate and spacing, we collected water applied directly near the fruit during cooling using containers with a known volume and surface area. Based on the amount of water applied in a given amount of time and area, we obtained a water application factor: $A$ (measured in liters per square meter per second). Therefore, $E_{w}$ was redefined as

$$
E_{w}^{\prime}=A \times f \times\left(T_{w}-T_{f}\right),
$$

where $f$ is a unit for cooling time. In general, fruit temperature declines over time during cooling. However, because fruit temperature was calculated using weather data measured in drip-irrigated plots, the result could not reflect the accumulation of heat removal over time. To solve this issue, $f$ was added to estimate changes in fruit temperature over consecutive time series. During each cooling cycle (i.e., the "on" time), heat removal from the previous cooling cycles was added by 1 unit of $f$. On the other hand, between cycles (i.e., the "off" time), $f$ decreased over time as a result of evaporation of water from the fruit surface. The water application factor during "off" times $\left(A_{\text {off }}\right)$ was calculated based on the amount of water applied during "on" times and the amount of time required for all water to evaporate from the fruit surface. The time required for evaporation was based on empirical observations. During cooling, it took $\approx 55 \mathrm{~min}$ for the fruit to dry after $15 \mathrm{~min}$ of water application. Therefore, $A_{\mathrm{off}}=$ $A_{\text {on }} \times($ On time $) \div$ (Time required for evaporation) $=0.0102 \mathrm{~L} \cdot \mathrm{m}^{-2} \cdot \mathrm{s}^{-1} \times 15 \mathrm{~min} \div$ $55 \mathrm{~min}=0.0028 \mathrm{~L} \cdot \mathrm{m}^{-2} \cdot \mathrm{s}^{-1}$.

Weather data collected from the field were entered into the equations. Fruit temperature was then calculated at 5-min time intervals using Excel Solver (Microsoft, 


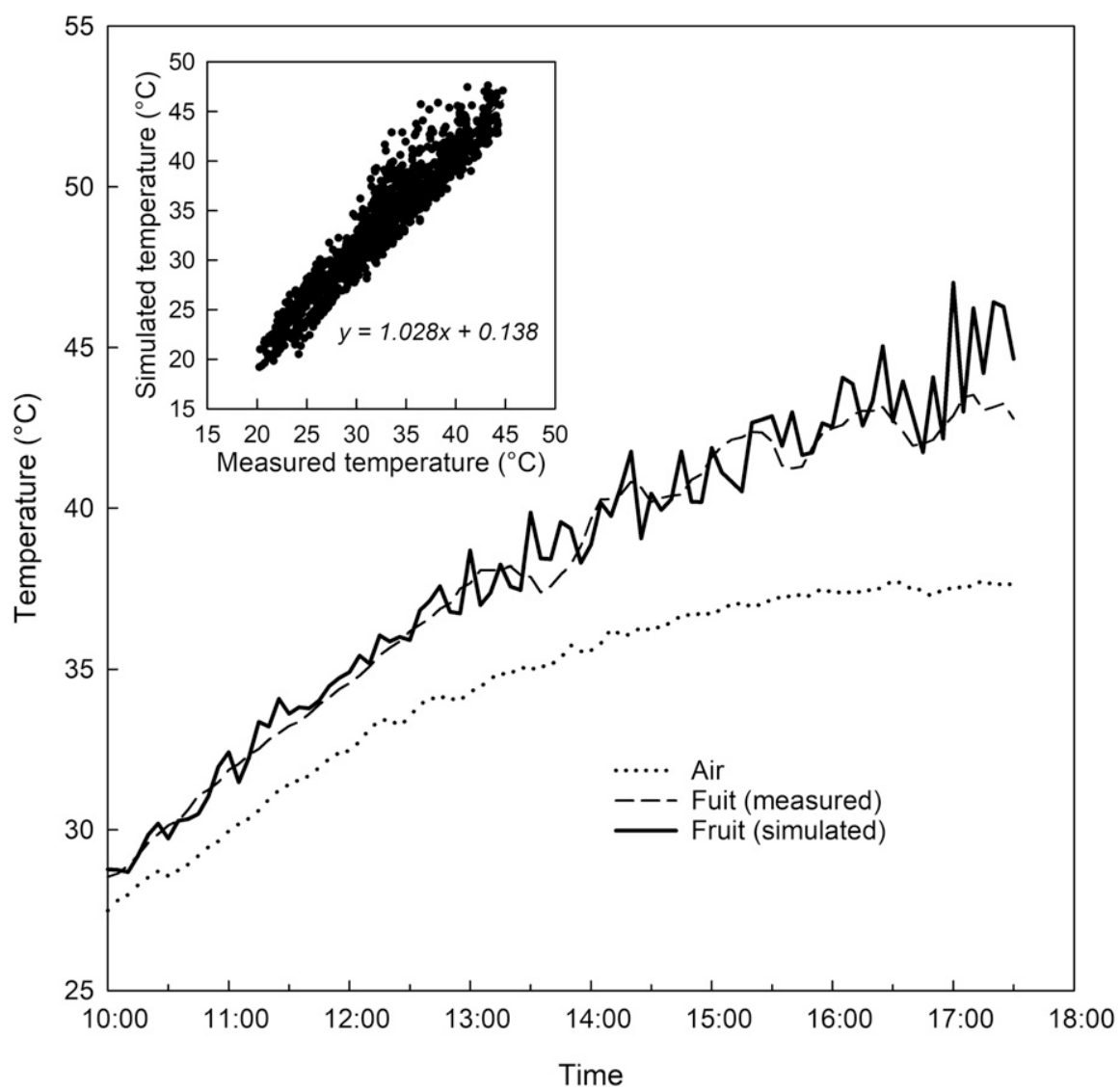

Fig. 2. Comparison of model results to actual surface temperature of sun-exposed blueberries measured in a field of 'Elliott' blueberry on 31 July 2015 (hottest day of the year). (Inset) The relationship between simulated and measured fruit temperatures (5-min time step) for 13 sunny days in 2015.

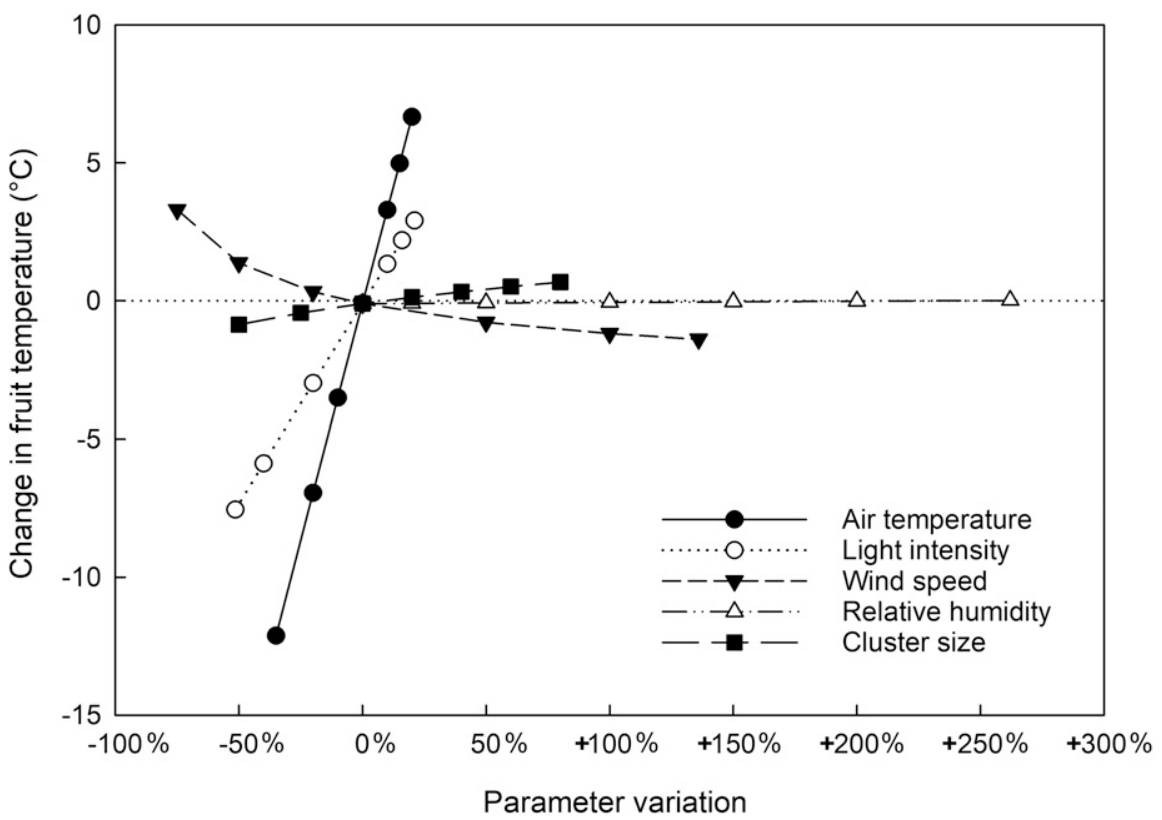

Fig. 3. Sensitivity analysis of various physical parameters in the energy balance model on estimates of fruit surface temperature. Range of each parameter: air temperature $\left(25\right.$ to $\left.46^{\circ} \mathrm{C}\right)$, light intensity $(400-1000$ $\left.\mathrm{W} \cdot \mathrm{m}^{-2}\right)$, wind speed $\left(1-10 \mathrm{~m} \cdot \mathrm{s}^{-1}\right)$, relative humidity $(16 \%$ to $60 \%)$, and cluster size $(5-18 \mathrm{~cm})$.

Seattle, WA), because the berry temperature is implicit in these equations and can only be solved for using iterative methods. Solver is an add-in program used for what-if analysis.
Energy parameters $\left(R_{a b s}, R_{e}, H, \lambda E, E_{f}\right.$, and $E_{w}$ ) were initially calculated at a fruit temperature of $25^{\circ} \mathrm{C}$. The sum of these parameters was then set to zero, and fruit temperature was set up as a changing variable. Solver automatically found the bestfitting fruit temperature by optimizing the result based on minimizing the sum of squared errors. A sensitivity analysis was performed to evaluate the impact of different variables on the model output, including air temperature, light intensity, wind speed, relative humidity, and diameter of the berry cluster (cluster size). To test the weight of each variable, one factor was changed at a time, and the output was monitored. Based on data from the hottest day of year, the parameters were initially set at $38{ }^{\circ} \mathrm{C}, 826 \mathrm{~W} \cdot \mathrm{m}^{-2}$, $4.2 \mathrm{~m} \cdot \mathrm{s}^{-1}$ (classified as a "gentle breeze," according to the Beaufort scale), $16 \%$, and $0.1 \mathrm{~m}$, respectively.

\section{Results}

Validation of the model. The model was validated using data collected on 13 sunny days in July and Aug. 2015. Throughout the course of each day, berry temperatures predicted by the model tended to fluctuate frequently relative to the actual measurements; but, in general, remained within a few degrees of the temperatures measured in the field (Fig. 2). Fluctuations in the simulated values were the result of minor changes in wind speed, which is a key parameter for estimating heat transfer (Eq. [4]) and boundary layer thickness (Eq. [8]) on the berry clusters. The relationship between the predicted and actual temperature was linear $(P<$ $0.0001)$ and had a coefficient of determination ( $R^{2}$ value) of 0.91 and a root meansquare error of $2.1^{\circ} \mathrm{C}$ (Fig. 2, inset). Tests for normality and constant variance, however, failed $(P<0.0001)$. Most of the variability occurred at temperatures higher than $30^{\circ} \mathrm{C}$ and was likely a result of periodic shading of the berries, produced by nearby leaves or by adjacent berries on the cluster, as the sun moved across the sky.

Sensitivity analysis indicated that estimates of berry temperature were largely affected by air temperature, light intensity, and wind speed, and were only slightly influenced by relative humidity or size of the berry cluster (Fig. 3). For example, adjusting air temperature in the model from 34 to $38{ }^{\circ} \mathrm{C}$ $(+11 \%$ gain) increased our estimate of berry temperature by $3.5^{\circ} \mathrm{C}$. Likewise, a $10 \%$ gain in light intensity increased berry temperature by $1.4{ }^{\circ} \mathrm{C}$. In both cases, the relationship between the variation in these parameters and changes in fruit temperature was linear. Wind speed was the only factor that correlated negatively with fruit temperature. In this case, the relationship was sigmoidal and dominated by the boundary layer on the fruit cluster. Consequently, berry temperature was affected much more by changes in wind speed under light-breeze conditions (1.6-3.3 $\left.\mathrm{m} \cdot \mathrm{s}^{-1}\right)$ than under a moderate breeze $(5.5-7.9$ $\left.\mathrm{m} \cdot \mathrm{s}^{-1}\right)$. For example, reducing wind speed from 4.2 to $2.1 \mathrm{~m} \cdot \mathrm{s}^{-1}$ increased berry temperature by $1.5^{\circ} \mathrm{C}$, whereas increasing it from 4.2 to $8.5 \mathrm{~m} \cdot \mathrm{s}^{-1}$ reduced berry temperature by only $1.1^{\circ} \mathrm{C}$. Berry temperature was barely 


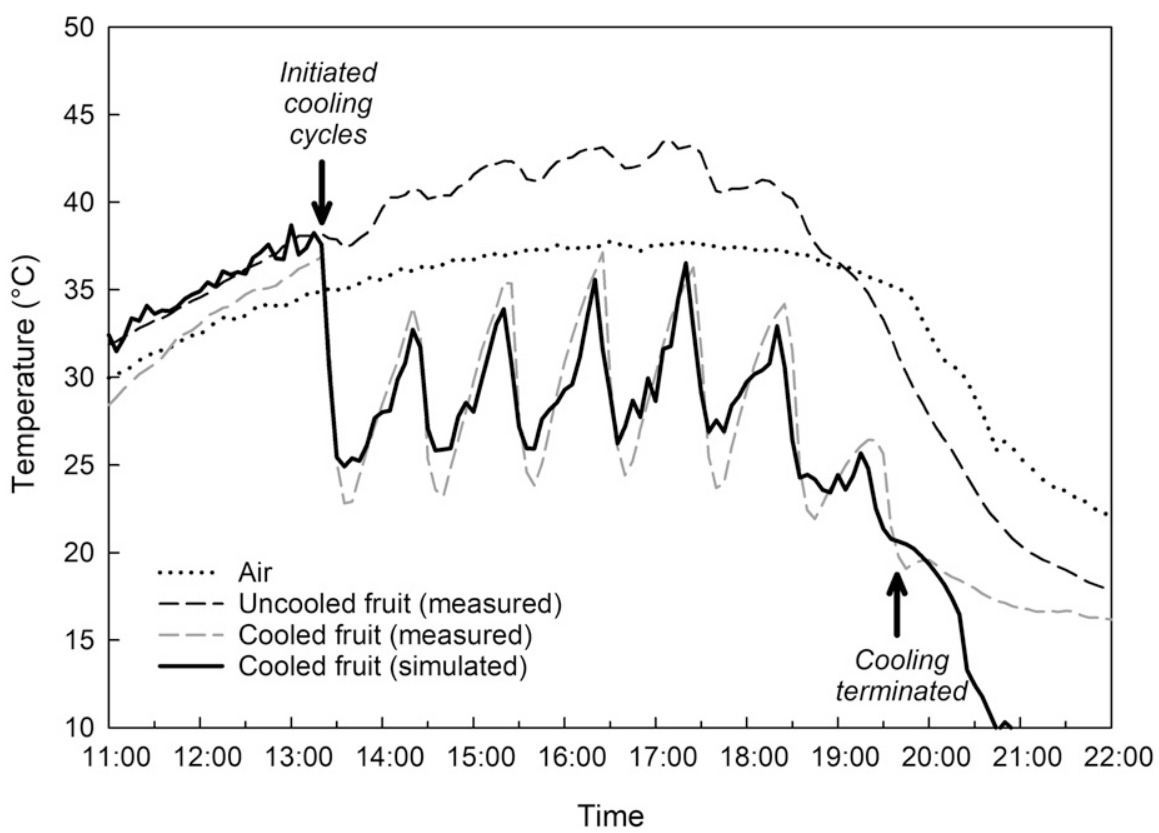

Fig. 4. Comparison of measured and simulated fruit surface temperatures during cooling with overhead sprinklers in a field of 'Elliott' blueberry on 31 July 2015 (hottest day of the year). Cooling was initiated when the air temperature reached $35^{\circ} \mathrm{C}(1320 \mathrm{HR})$ and was run for 15 min every hour until air temperature was once again $<35^{\circ} \mathrm{C}(1940 \mathrm{HR})$.

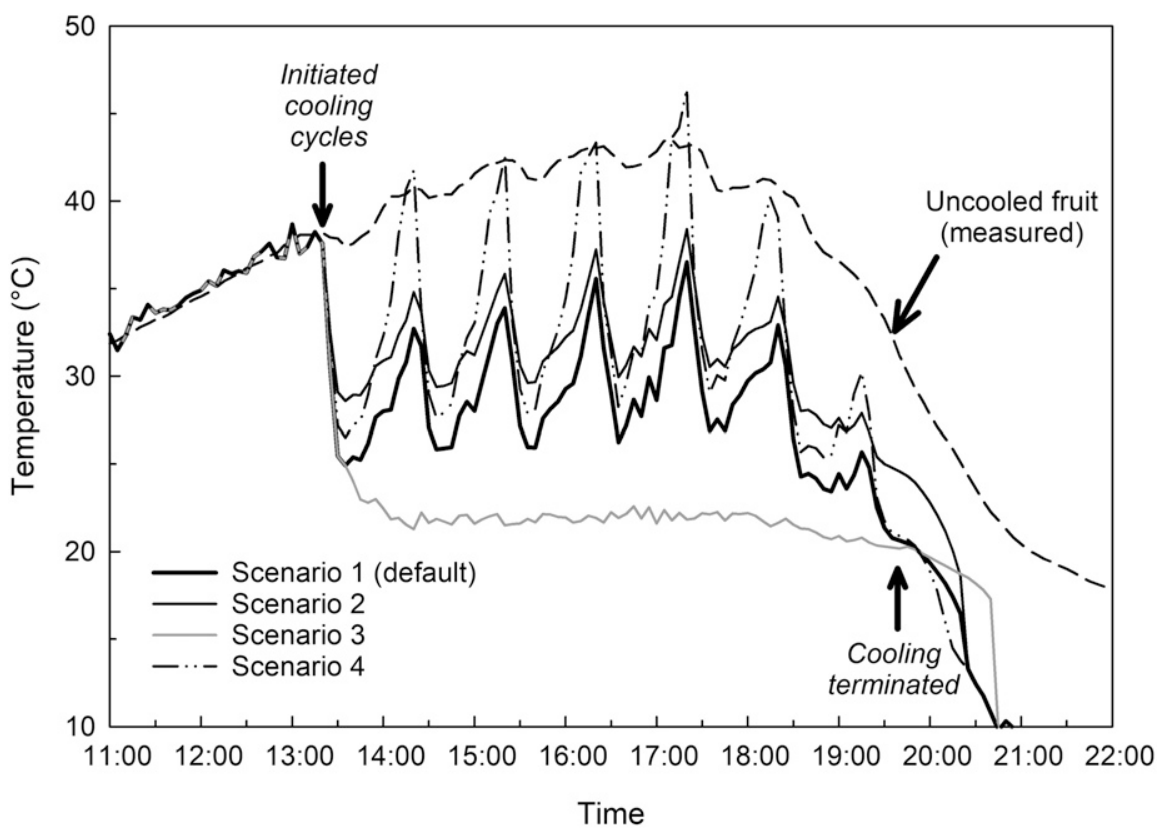

Fig. 5. Simulated fruit surface temperatures under different cooling scenarios with over-canopy sprinklers in northern highbush blueberry. In scenario 1, sprinklers were run for 15 min every hour, and temperature of the irrigation water was set at $20^{\circ} \mathrm{C}$. Sprinklers were also run for 15 min every hour in scenario 2, but water temperature was increased to $25^{\circ} \mathrm{C}$. In scenario 3 , sprinklers were run continuously at a water temperature of $20^{\circ} \mathrm{C}$. Scenario 4 was similar to scenario 1 , except in this case the rate of water application was reduced by $33 \%$. The first scenario was used as the default setting and was based on the parameters measured on 31 July 2015 (see Fig. 4). Measured temperatures of uncooled fruit were included as a reference.

affected by changes in relative humidity $\left(<0.1{ }^{\circ} \mathrm{C}\right)$ and, with the exception of very small berry clusters (e.g., 5-cm diameter), was only slightly affected by differences in cluster size $\left(<1^{\circ} \mathrm{C}\right)$.

Predicting fruit temperatures during cooling with sprinklers. Pulsed cooling with outset of cooling were initially quite similar to the actual berry temperatures measured in the field. However, unlike the predicted values, actual berry temperatures continued to drop by 2 to $3{ }^{\circ} \mathrm{C}$ each time irrigation was turned off during a cooling cycle, and often peaked at somewhat higher temperatures between cycles. Although fruit temperature during cooling was somewhat more variable than predicted by the model, mean differences between measured and simulated values were $<1.4{ }^{\circ} \mathrm{C}$ within each irrigation cycle. Because of the nature of the model, fruit temperature could not be predicted after sunset (2040 HR).

Based on Eq. [11], predicting the efficiency of cooling was primarily dependent on the temperature of the irrigation water and the rate and frequency at which the water was applied. To illustrate, we ran the model under four different operating scenarios (Fig. 5). The default was set to run sprinklers for 15 min every hour using water with a temperature of $20{ }^{\circ} \mathrm{C}$ (scenario 1). When temperature of the water was increased to $25^{\circ} \mathrm{C}$ (scenario 2), fruit temperature was $\approx 1$ to $3{ }^{\circ} \mathrm{C}$ warmer during cooling than in the previous scenario, but it was still well below the temperature of the uncooled fruit. Predictably, running sprinklers continuously (scenario 3 ) reduced fruit temperature to nearly the same temperature as the irrigation water (i.e., $20{ }^{\circ} \mathrm{C}$ ). The final scenario was an extreme case in which water applications were reduced by $33 \%$ (scenario 4 ). In this case, fruit temperature declined as expected during cooling but increased between cycles to the same temperature as the uncooled fruit.

\section{Discussion}

An energy balance model was developed in our study to predict changes in fruit temperature on warm, sunny days in northern highbush blueberry. It was not surprising that most of the energy gained from incoming solar radiation was lost in the form of emittance and sensible heat. Latent heat from transpiring berries only accounted for a small portion of the energy lost, which was likewise found in apple and grape ( $\mathrm{Li}$ et al., 2014; Saudreau et al., 2007; Smart and Sinclair, 1976). Like most fruit, blueberries have very few functioning stomata on the surface, particularly as the wax layers thicken during ripening (Yang et al., 2020b). During cooling with sprinklers, additional sensible heat was removed through contact between the fruit and the irrigation water applied. Using local weather data, estimates of fruit temperature during cooling were accurate.

Ambient air temperature was the most important variable affecting our estimates of berry temperature. Light intensity was also important, followed by wind speed and size of the berry cluster. Relative humidity had very little impact. Light intensity and air temperature are confounding factors, as incremental increases in light result in higher air temperatures. Fruit temperature, on the other hand, correlated negatively with wind 
speed. Faster wind speeds increase sensible heat loss and thereby reduce fruit temperature (Smart and Sinclair, 1976). Cluster size was of minor importance in our estimates of fruit temperature $\left(<1{ }^{\circ} \mathrm{C}\right)$. Fruit temperature increased with larger fruit (or clusters in our study) as a result of a thicker boundary layer (Patiño et al., 1994). Although relative humidity was also of minor importance $\left(<0.1^{\circ} \mathrm{C}\right)$, it would be interesting to investigate the response of fruit temperature to cooling in a hot and humid climate, such as Florida.

To simulate energy reception, estimates of fruit temperature were based on the assumption that the shape of a blueberry cluster is a sphere. For a spherical object, the direct beam of radiation received from sunlight varies with solar altitude. To simulate the hottest scenarios, we assumed the beam was normal to the fruit surface ("hot spot") (Smart and Sinclair, 1976). Although this correction proved to result in reasonable estimates of berry temperature during most of the day, it led to overestimates of incoming radiation in the early evening as a result of the low solar elevation angle near sunset (Smart and Sinclair, 1976). Although there is little risk of heat damage to the fruit during these times, based on our observations, we suggest users do not correct the total direct beam when the solar elevation angle is less than $20^{\circ}$. Instead, this angle should be calculated using the arctangent function and adjusted according to row direction, row spacing, and height of the plants in the field.

In our study, we assumed that a berry cluster is a thermal isotropic object. Previous results indicated there was a less than $1{ }^{\circ} \mathrm{C}$ difference between the surface and the center of a blueberry fruit on a sunny day (Yang et al., 2019). Therefore, temperature was measured and simulated only on the surface of the cluster. In apple, fruit temperatures were monitored separately at the skin and core, and heat conduction flux within the fruit was included in the energy balance model (Evans, 2004). In our case, heat storage accounted for a less than $0.5 \%$ total energy flux within the fruit and, therefore, was not included in the model. However, given the fact that temperature gradients normally occur within a blueberry cluster, more precise fruit temperature predictions could be achieved potentially by either estimating the light interception ratio of different clusters using a thermal camera (Li et al., 2014) or by modeling the upper and lower hemisphere of a fruit cluster separately (Saudreau et al., 2007; Smart and Sinclair, 1976).

We noted that actual fruit temperatures continued to decline by 2 to $3{ }^{\circ} \mathrm{C}$ after the sprinklers were turned off during each cooling cycle. This effect was likely a result of evaporation of water from the fruit surface, which removes a large amount of heat (2.43 $\mathrm{MJ} \cdot \mathrm{kg}^{-1}$ of water at $30{ }^{\circ} \mathrm{C}$ ). In the current model, the time required for water to evaporate from the fruit was based on visual observations, which may be why the simulations failed to account for the additional heat loss. Perhaps a surface wetness sensor could be used to improve the estimates. Hewett and Young (1980) reported that leaf wetness sensors could be used to control evaporative cooling systems for delaying bloom in fruit trees in the springtime. Leaf wetness sensors can also be connected to dehumidifying devices to reduce high relative humidity inside a greenhouse (Seginer and Zlochin, 1997). However, a preliminary study revealed that leaf wetness sensors tended to dry faster than a typical berry cluster (F.-H. Yang, unpublished data). A correlation between leaf wetness and water retention on the surface of the fruit would need to be developed to use this type of sensor for estimating fruit temperatures and scheduling cooling in a blueberry field.

In blueberry, most heat damage occurs on berries exposed to full sunlight (Yang et al., 2019), which is why the current model focused on predicting temperatures of sunexposed fruit. However, unlike in wine grape vineyards and high-density apple orchards, which rely on training practices to maximize fruit light exposure, berry clusters in blueberry are located throughout the canopy. Clusters located at lower or shaded positions generally have much lower fruit temperatures during the day than those located in the sun (Yang et al., 2019). Thus, scheduling cooling practices based on estimates of fully exposed clusters could result in wetter fruit in the shaded areas of the canopy and thereby increase the potential for infection by fungal pathogens. More work is needed to adjust for variations in cluster temperature.

Two significant outcomes were achieved in this study. First, a simple energy balance model was used successfully to predict fruit temperature based on local weather measurements. Potentially, this model can be incorporated into a weather forecast program to predict the incidence of heat damage on any given day. Second, the model predicted successfully the fruit temperature patterns during evaporative cooling practices and, therefore, could be used as a useful tool for making cooling decisions and evaluating the best cooling practices for northern highbush blueberry.

\section{Literature Cited}

Campbell, G.S. and J.M. Norman. 1998. An introduction to environmental biophysics. Springer-Verlag, New York, NY, doi: 10.1007/ 978-1-4612-1626-1.

Caravia, L., V. Pagay, C. Collins, and S.D. Tyerman. 2017. Application of sprinkler cooling within the bunch zone during ripening of Cabernet Sauvignon berries to reduce the impact of high temperature. Austral. J. Grape Wine Res. 23:48-57, doi: 10.1111/ajgw.12255.

Cellier, P., F. Ruget, M. Chartier, and R. Bonhomme. 1993. Estimating the temperature of a maize apex during early growth stages. Agr. For. Meteorol. 63:35-54, doi: 10.1016/01681923(93)90021-9.

Cola, G., O. Failla, and L. Mariani. 2009. BerryTone: A simulation model for the daily course of grape berry temperature. Agr. For. Meteorol. 149:1215-1228, doi: 10.1016/j.agrformet.2009. 01.007 .
Evans, R.G. 2004. Energy balance of apples under evaporative cooling. Amer. Soc. Agr. Eng. 47:1029-1037, doi: 10.13031/2013.16576.

Greer, D.H. and M.M. Weedon. 2014. Does the hydrocooling of Vitis vinifera cv. Semillon vines protect the vegetative and reproductive growth processes and vine performance against high summer temperatures? Funct. Plant Biol. 41:620-633, doi: 10.1071/FP13286.

Hewett, E.W. and K. Young. 1980. Water sprinkling to delay bloom in fruit trees. N. Z. J. Agr. Res. 23:523-528, doi: 10.1080/00288233.1980. 10417877.

Houston, L., S. Capalbo, C. Seavert, M. Dalton, D. Bryla, and R. Sagili. 2018. Specialty fruit production in the Pacific Northwest: Adaptation strategies for a changing climate. Clim. Change 146:159-171, doi: 10.1007/s10584017-1951-y.

Iglesias, I., J. Salvia, L. Torguet, and C. Cabús. 2002. Orchard cooling with overtree microsprinkler irrigation to improve fruit colour and quality of 'Topred Delicious' apples. Scientia Hort. 93:39-51, doi: 10.1016/S0304-4238(01) 00308-9.

Kliewer, W.M. and H.B. Schultz. 1973. Effect of sprinkler cooling of grapevines on fruit growth and composition. Amer. J. Enol. Viticult. 24:17-26.

Li, L., T. Peters, Q. Zhang, J. Zhang, and D. Huang. 2014. Modeling apple surface temperature dynamics based on weather data. Sensors 14:20217-20234, doi: 10.3390/s141120217.

Lobos, G.A. and J.F. Hancock. 2015. Breeding blueberries for a changing global environment: A review. Front. Plant Sci. 6:782, doi: 10.3389/ fpls.2015.00782.

Mercali, G.D., J.R. Sarkis, D.P. Jaeschke, I.C Tessaro, and L.D.F. Marczak. 2011. Physical properties of acerola and blueberry pulps. J. Food Eng. 106:283-289, doi: 10.1016/j.jfoodeng.2011.05.010.

Monteith, J. and M. Unsworth. 2013. Principles of environmental physics: Plants, animals and the atmosphere. 4th ed. Academic Press, San Diego, CA, doi: 10.1016/B978-0-12-3869104.00013-5.

Nobel, P.S. 1975. Effective thickness and resistance of the air boundary layer adjacent to spherical plant parts. J. Expt. Bot. 26:120-130, doi: $10.1093 / \mathrm{jxb} / 26.1 .120$.

Parchomchuk, P. and M. Meheriuk. 1996. Orchard cooling with pulsed overtree irrigation to prevent solar injury and improve fruit quality of 'Jonagold' apples. HortScience 31:802-804, doi: 10.21273/HORTSCI.31.5.802.

Patiño, S., E.A. Herre, and M.T. Tyree. 1994. Physiological determinants of Ficus fruit temperature and implications for survival of pollinator wasp species: Comparative physiology through an energy budget approach. Oecologia 100:13-20, doi: 10.1007/BF00317125.

Pelletier, V., S. Pepin, J. Gallichand, and J. Caron. 2016. Reducing cranberry heat stress and midday depression with evaporative cooling. Scientia Hort. 198:445-453, doi: 10.1016/j.scienta.2015.12.028.

Pitacco, A., C. Giulivo, and F. Iacono. 2000 Controlling vineyard energy balance partition by sprinkling irrigation. Acta Hort. 537:121128, doi: 10.17660/ActaHortic.2000.537.11.

Saudreau, M., A. Marquier, B. Adam, P. Monney, and H. Sinoquet. 2009. Experimental study of fruit temperature dynamics within apple tree crowns. Agr. For. Meteorol. 149:362-372, doi: 10.1016/j.agrformet.2008.09.001

Saudreau, M., H. Sinoquet, O. Santin, A. Marquier, B. Adam, J.-J. Longuenesse, L. Guilioni, and M. Chelle. 2007. A 3D model for simulating the 
spatial and temporal distribution of temperature within ellipsoidal fruit. Agr. For. Meteorol. 147:115, doi: 10.1016/j.agrformet.2007.06.006.

Seginer, I. and I. Zlochin. 1997. Night-time greenhouse humidity control with a cooled wetness sensor. Agr. For. Meteorol. 85:269-277, doi: 10.1016/S0168-1923(96)02387-8.

Smart, R.E. and T.R. Sinclair. 1976. Solar heating of grape berries and other spherical fruits. Agr. Meteorol. 17:241-259, doi: 10.1016/00021571(76)90029-7.
Yang, F.-H., D.R. Bryla, and B.C. Strik. 2019. Critical temperatures and heating times for fruit damage in northern highbush blueberry. HortScience 54:2231-2239, doi: 10.21273/HORTSCI 14427-19.

Yang, F.-H., D.R. Bryla, S.T. Orr, B.C. Strik, and Y. Zhao. 2020a. Thermal cooling with sprinklers or microsprinklers reduces heat damage and improves fruit quality in northern highbush blueberry. HortScience 55:1355-1371, doi: 10.21273/HORTSCI15119-20.
Yang, F.-H., L.W. DeVetter, B.C. Strik, and D.R. Bryla. 2020b. Stomatal functioning and its influence on fruit calcium accumulation in northern highbush blueberry. HortScience 55:96-102, doi: 10.21273/HORTSCI1448219.

Zhang, Y. and M. Keller. 2015. Grape berry transpiration is determined by vapor pressure deficit, cuticular conductance, and berry size. Amer. J. Enol. Viticult. 66:454 462, doi: 10.5344/ ajev.2015.15038. 